\title{
In vitro and in vivo evaluation of 2-aminoalkanol and 1,2-alkanediamine derivatives against Strongyloides venezuelensis
}

Ana L. Legarda-Ceballos', Julio López-Abán ${ }^{1 *}$, Esther del Olmo², Ricardo Escarcena², Luis A. Bustos ${ }^{2,3}$, Jose Rojas-Caraballo ${ }^{1,4,5}$, Belén Vicente ${ }^{1}$, Pedro Fernández-Soto ${ }^{1}$, Arturo San Feliciano ${ }^{2}$ and Antonio Muro ${ }^{1}$

\begin{abstract}
Background: Strongyloidiasis is a parasitic disease widely present in tropical and subtropical areas. Strongyloides stercoralis represents the main species that infects human beings. Ivermectin is the current drug of choice; however, issues related with treatment failure in patients with diabetes or infected with T-lymphotropic virus-1 make the identification of new molecules for alternative treatment a priority. In the present study, the activity of sphingosine-related aminoalcohol and diamine were evaluated against Strongyloides venezuelensis third-stage larva (L3) cultures and experimental infections in mice.
\end{abstract}

Methods: The efficacy of each compound against L3 was assessed using both XTT (2,3-bis-(2-methoxy-4-nitro-5sulfophenyl)-2H-tetrazolium-5-carboxanilide) assay and microscopic observation with concentrations ranging from

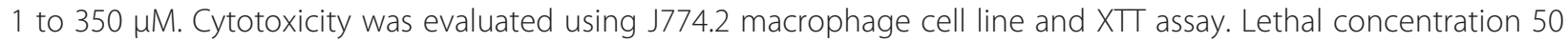
$\left(\mathrm{LC}_{50}\right)$, selectivity index $(\mathrm{SI})$ and structure-activity relationships were established. The activity compounds 4 (2-(ethylamino) hexadecan-1-ol), 6 (2-(butylamino) hexadecan-1-ol), 17 (tert-butyl N-(1-aminododecan-2-yl) carbamate) and 18 (tert-butyl $\mathrm{N}$-(1-aminohexadecan-2-yl) carbamate) were further assessed against experimental S. venezuelensis infections in CD1 mice measuring reductions in the numbers of parthenogenetic females and egg passed in faeces. Mice were infected with 3,000 L3 and treated with 20 mg/kg/day for five days.

Results: In the screening study of 15 aminoalcohols [lauryl $(n=9)$; palmityl $(n=13)$; stearyl $(n=15)$ and alcohol derivatives], the presence of a palmitol chain was associated with the highest efficacy against L3 (LC 50 31.9-39. $1 \mu \mathrm{M})$. Alkylation of the 2-amino group with medium size fragments as ethyl or n-butyl showed the best larvicidal activity. The dialkylation did not improve efficacy. Aminoalcohols 4 and 6 showed the highest SI (1.5 and 1.6, respectively). With respect to diamine derivative compounds, a chain size of sixteen carbon atoms (palmitoyl chain, $n=13$ ), and the alkylation of the 2-amino group with medium-sized fragments, were associated with the highest lethal activities. The presence of carbamoyl group in diamines 17 and 18 yielded high SI (1.7 and 1.4, respectively). Infected mice treated with aminoalcohol 6 showed reduction in parthenogenetic females (59 \%) and eggs in faeces (51 \%).

Conclusions: These results support the potentiality of aminoalcohol and diamine sphingosine-related compounds as suitable prototypes for developing new promising drugs against strongyloidiasis.

Keywords: Strongyloidiasis, Treatment, Alkaneaminoalcohol, Alkanediamine, Anthelmintics

\footnotetext{
* Correspondence: jlaban@usal.es

${ }^{1}$ Parasite and Molecular Immunology Laboratory, Tropical Disease Research

Centre, University of Salamanca (IBSAL-CIETUS), Avda. Licenciado Méndez

Nieto s/n, 37007 Salamanca, Spain

Full list of author information is available at the end of the article
} 


\section{Background}

Strongyloidiasis is a parasitic disease caused by nematodes of the genus Strongyloides, which are widely present in tropical and subtropical areas with climate suitable for the survival of larval stages of the species of this genus. The main species causing the disease in the human beings is Strongyloides stercoralis and it is estimated that 30 to 100 million people are infected around the world [1]. Strongyloidiasis is also classified as a Neglected Tropical Disease, according to the World Health Organization [2, 3]. This parasite has a complex life-cycle: larvae penetrate the skin of the host and migrate through the bloodstream to the lungs, where they enter into the alveolar spaces, ascending to the respiratory tree, the trachea, the pharynx and finally migrate back through the oesophagus and stomach into the intestine where they reach maturity [4-6]. Parthenogenetic females inhabit the mucosa of the small intestine where the eggs are laid. The rhabditiform larvae (L1) are eliminated together with faeces and develop over a few days in temperate and humid environment to infective third-stage filariform larvae (L3). Minimally symptomatic chronic infection and cutaneous, respiratory or gastrointestinal signs are observed in patients. Strongyloides stercoralis has also the ability to cause systemic disseminated infection and hyperinfection syndrome in immunocompromised humans. In most of these cases the outcome of the disease is fatal $[7,8]$.

Ivermectin is an effective well-tolerated drug against strongyloidiasis, reaching cure rates of 93.1-96.8 \% with one single dose administration [9]. On the other hand, treatment failure has been observed in patients coinfected with $S$. stercoralis and human T-lymphotropic virus-1 (HTLV-1) [10] and concomitancy with diabetes [11]. Albendazole, mebendazole and thiabendazole given in multiple doses are also used for the treatment of strongyloidiasis but their efficacy and tolerability is not as efficient as ivermectin [12,13]. The concern about decreased efficacy in human nematodosis and the possibility of acquired-resistance in treatments of human nematodes is increasing $[14,15]$. Additionally, rare population genotypes have shown encephalopathy when treated against Loa loa infections with ivermectin [16] making the discovery of new alternative nematicidal drugs a high priority challenge.

Long chain aminoalcohols and diamine derivatives are sphingosine-related compounds considered as key molecules for designing alternative drugs to the current treatment of infectious diseases. Biocidal activity of these compounds has been reported against bacteria such as Mycobacterium tuberculosis [17], protozoans such as Plasmodium spp. [18] Leishmania spp. [19], Trypanosoma brucei [20], T. cruzi [21], Trichomonas vaginalis, Giardia lamblia [22], fungi [23] and helminths such as Schistosoma mansoni [24] or the nematode Caenorhabditis elegans [25].
Alkylphospholipids are molecules structurally related to long-chain aminoalcohols and diamines with promising anticancer, antiprotozoal and anthelminthic activity. Their activity is exerted through the interaction with cell membranes, activating apoptosis [26].

In the present study, we have synthesized and evaluated the anti-Strongyloides activity of two series of sphingosine derivative compounds including aminoalcohol and diamine derivatives. We have studied their effect on cultures of third-stage $S$. venezuelensis larvae, and those compounds showing good activity were selected to assess their efficacy against $S$. venezuelensis in experimental infections in mice. We also studied cytotoxicity and structure-activity relationships of these aminoalchol and diamine derivatives.

\section{Methods}

Animals and ethics statement

Animal procedures complied with the European Union (Di 2010/63/CE) and the Spanish (L32/2007, L6/2013, RD53/2013) regulations on animal experimentation. The University of Salamanca's Ethics Committee also approved the procedures that were used in this study (Protocol: 48531). Male Wistar rats weighing 80-120 g from the Animal Experimentation facilities of the University of Salamanca (Registration No. PAE/SA/001) and male Specific Pathogen Free (SPF) CD1 mice (Charles River, Barcelona, Spain) weighing 25-30 g were used for the maintenance of $S$. venezuelensis life-cycle and for in vivo experiments in standard conditions. Size of groups was calculated by power analysis [27] using "size.fdr" package for $\mathrm{R}$ and following the 3Rs recommendations [28].

\section{Maintaining Strongyloides venezuelensis life-cycle and parasitological techniques}

The $S$. venezuelensis strain from the Department of Parasitology (University of Minas Gerais, Belo Horizonte, Brazil) was maintained at the University of Salamanca (biosecurity protocol No. 15/019) by serial in vivo passages in Wistar rats. The infective third-stage larvae (L3) of S. venezuelensis were obtained from 3 to 4 dayold vermiculite cultures of faeces from infected rats using a Baermann apparatus. L3 were decontaminated according to the methodology previously reported by Martins et al. [29]. Freshly obtained L3 were washed six times, for twenty minutes each, with distilled water containing $100 \mathrm{IU} / \mathrm{ml}$ penicillin, $0.1 \mathrm{mg} / \mathrm{ml}$ streptomycin and $0.8 \mathrm{mg} / \mathrm{ml}$ fluconazole. Absence of bacterial contamination was confirmed by culturing larvae from each batch on a Petri dish containing blood agar at $28^{\circ} \mathrm{C}$ during $24 \mathrm{~h}$. Wistar rats were infected with $6,000 \mathrm{~L} 3$ in $0.5 \mathrm{ml}$ phosphate buffered saline (PBS) using a 23-gauge needle syringe to maintain the life-cycle. To perform faecal egg counts, mice were placed on grids over clean moist absorbent paper and allowed to defecate. Individual faecal 
samples were collected, conserved in a $10 \% v / v$ formalin buffered solution and counted in triplicate under a microscope using McMaster technique and egg per gram were reported. The upper half of the small intestine was removed after euthanasia (pentobarbital $100 \mathrm{mg} / \mathrm{kg}$ ), minced and placed in a sedimentation cup wrapped by 8 layers of gauze in PBS for $2 \mathrm{~h}$ at $37{ }^{\circ} \mathrm{C}$. The parthenogenetic females were then collected from the sediment and their number recorded.

\section{Drugs and sample preparation}

The procedures for the synthesis of 2-aminoalkan-1-ol (type I; compounds 1-15) and alkane 1,2-diamine (type II; compounds 16-25) derivatives, which are structurally related to sphingosine, were previously reported (Fig. 1) $[17,19,20,30]$. Fifteen aminoalcohol and ten diamine derivatives were synthesized. Compounds were solubilized in dimethyl sulfoxide (DMSO) and appropriate dilutions were made to perform assays. Edelfosine (1$O$-octadecyl-2-O-methyl-rac-glycero-3-phosphocholine) was obtained from R. Berchtold (Biochemisches Labor, Bern, Switzerland) and used as reference for in vitro studies. Ivermectin was purchased from Sigma (St Louis, MO, USA) and used as a reference drug for the in vivo treatment of strongyloidiasis.

\section{Cytotoxicity assessment in mouse macrophage cultures}

The J774.2 mouse-derived peritoneal macrophage cell line was used to assess the cytotoxicity of the compounds. Macrophages were grown and serial successive in vitro passages were performed according to the methodology previously described by Rojas-Caraballo et al. [31]. To study the cytotoxicity of each compound, $200 \mu \mathrm{l}$ of a suspension containing $1 \times 10^{5}$ cells $/ \mathrm{ml}$ were added onto 96 well flat-bottom microplates, allowed to adhere to the surface of the plate for $2 \mathrm{~h}$ at $37^{\circ} \mathrm{C}, 5 \% \mathrm{CO}_{2}$ and then exposed to the compounds for $72 \mathrm{~h}$ at the following concentrations: $0.1 ; 0.5 ; 3.3 ; 15.0 ; 35.0$; and $70.0 \mu \mathrm{M}$. Each concentration was assayed at least in triplicate in three independent experiments. Cytotoxicity was evaluated based on the colorimetric 2,3-bis-(2-methoxy-4-nitro-5-sulfophenyl)-2Htetrazolium-5-carboxanilide (XTT) assay. After the treatment, $50 \mu \mathrm{l}$ of XTT solution were added to each individual well and plates were incubated for $24 \mathrm{~h}$ at $37{ }^{\circ} \mathrm{C}$. The absorbance of the plate was then measured at $492 \mathrm{~nm}$ using an ELISA-plate reader (Anthos Labtec Instruments, Wals, Austria). Results were expressed as the percentage of macrophages remaining alive after each treatment. Untreated and DMSO-treated macrophages were used as controls. Each concentration was assayed in triplicate in three independent experiments and the $\mathrm{LC}_{50}$ value for each compound was calculated by sigmoidal regression analysis [32].

\section{Efficacy and structure-activity study relationship of compounds against third-stage larva cultures}

A hundred decontaminated L3 in water were added to 96-well flat bottom microplates. Each compound was added at $1,10,35,70$ and $350 \mu \mathrm{M}$ and then incubated during $72 \mathrm{~h}$ at $28{ }^{\circ} \mathrm{C}$ in triplicate and in a minimum of three independent experiments. Larval viability was quantified both by using the colorimetric XTT assay as described above and by monitoring larval motility at 24, 48 and $72 \mathrm{~h}$ post-treatment. Larval movement was recorded after stimulation with direct natural light for 2 min using an inverted microscope (CK2, Olympus, Tokio, Japan) and a video recorder (AM423 camera and DinoCapture 2.0 software, Dino-Lite digital microscope, Naarden, Holland). Larvae were considered dead when no movement was detected for at least two minutes of detailed examination. As controls, L3 were incubated in water or treated with edelfosine in a range of $1-350 \mu \mathrm{M}$. Results were expressed as the concentration of each compound able to inhibit $50 \%$ of total larvae movement $\left(\mathrm{LC}_{50}\right)$, calculated by sigmoidal regression analysis [32]. Selectivity Index (SI) was calculated as the ratio between the $\mathrm{LC}_{50}$ value of each compound in macrophage culture and the $\mathrm{LC}_{50}$ in $\mathrm{L} 3$ cultures to compare the efficacy and toxicity of each compound. Potency relative to edelfosine $\left(\mathrm{P}_{\mathrm{EDEL}}\right)$ was calculated as the ratio between edelfosine- $\mathrm{LC}_{50}$ and $\mathrm{LC}_{50}$ of each compound. Edelfosine, a sphingosine-related compound, was used based on the low toxicity and high in vitro activity against helminths observed in previous experiments in our laboratory [33] The influence of the side-chain size, the substitution of the 2-amino group, and the presence of a free hydroxyl function or a benzyl ether on the activity of each compound were studied in compounds of type I.
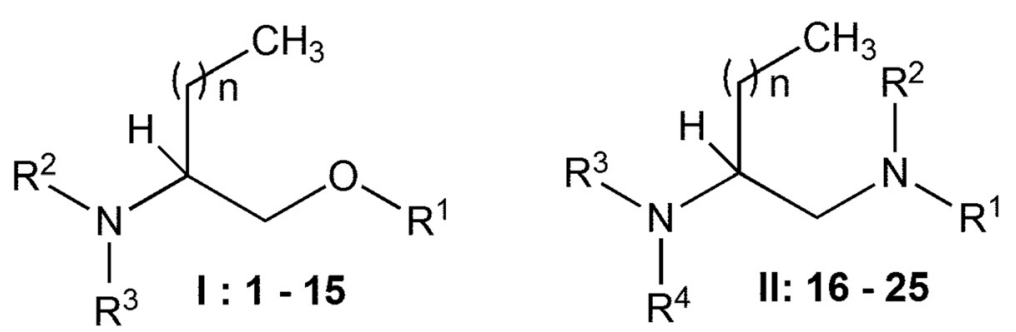

Fig. 1 General structures for aminoalcohol derivatives (type I, compounds 1-15) and diamine derivatives (type II, compounds 16-25) 
The influence of the substituents on the 1-amino group and the presence of a tert-butoxycarbonyl (Boc) protecting group on the 2-amino group have also been examined in type II compounds.

\section{Assessment of efficacy against S. venezuelensis infection in mice}

Those compounds showing the best activity against L3 in the screening test (aminoalcohols $\mathbf{4}$ and $\mathbf{6}$, and diamines $\mathbf{1 7}$ and 18) were tested in S. venezuelensis experimental infections of mice. For this purpose, we used a total of 64 male CD1 mice randomly distributed in groups of eight animals. We performed two independent experiments with four groups each: infection control, infected and treated with ivermectin and two groups infected and treated with their respective selected compound. In the first experiment, the aminoalcohols $\mathbf{4}$ and 6 were tested and in the second experiment the diamines $\mathbf{1 7}$ and $\mathbf{1 8}$ were tested. All mice were subcutaneously infected with 3,000 L3 of S. venezuelensis prior to drug treatment. Ivermectin was orally administered with a single standard dose of $0.2 \mathrm{mg} / \mathrm{kg}$ on day 5 postinfection (p.i.). Aminoalcohols and diamines were orally administered with a dose of $20 \mathrm{mg} / \mathrm{kg} /$ day at the day of infection and during the next five days to let reaching therapeutical concentration after day 5 p.i. Doses were determined on the basis of the cytotoxicity and previous experience in our laboratory with using sphingosinerelated compounds [23, 34]. The number of parasitic females in the gut on day 7 p.i. and the number of eggs released in the faeces during the experiment were quantified to evaluate the efficacy of the treatment.

\section{Statistical analysis}

The results were expressed as the mean and the standard error of the mean (SEM). Normality of data distribution was assessed by the non-parametric Kolmogorov-Smirnov test and the homogeneity of variance was tested by the Barrett test. Significant differences between groups were found using one-way ANOVA followed by Tukey's honest significance test. All statistical analyses were considered significant at a $P$-value $<0.05$. All analyses and graphics were performed with Prism 5 (GraphPad Software, San Diego, CA) for Mac.

\section{Results}

Efficacy of aminoalcohols and diamines against $S$. venezuelensis $\mathrm{L} 3$

Concerning the in vitro activity against $S$. venezuelensis larvae of the aminoalcohol derivatives (compounds 1-15 in Table 1), compounds $\mathbf{4}$ and $\mathbf{6}$ showed the highest larvicidal activity $\left(\mathrm{LC}_{50}=35.1 \pm 0.1\right.$ and $31.9 \pm 0.5 \mu \mathrm{M}$, respectively), that is 1.4 and 1.5 times, respectively, more potent than edelfosine $\left(\mathrm{LC}_{50}=49.6 \pm 0.5 \mu \mathrm{M}\right)$ but less than ivermectin $\left(\mathrm{LC}_{50}=0.46 \pm 0.1 \mu \mathrm{M}\right)$ after $72 \mathrm{~h}$ of culture. Compounds $\mathbf{4}$ and $\mathbf{6}$ had cytotoxicity values of $\mathrm{LC}_{50}=52.0 \pm 5.3 \mu \mathrm{M}$ and $\mathrm{LC}_{50}=52.0 \pm 4.1 \mu \mathrm{M}$, respectively, which were also less toxic than edelfosine or ivermectin for macrophages $\left(\mathrm{LC}_{50}=40.7 \pm 7.1\right.$ and $1.1 \pm$ $0.1 \mu \mathrm{M}$, respectively). The SI for edelfosine and ivermectin were 0.8 and 2.4 , respectively, while for compounds 4 and 6 the SI were 1.5 and 1.6, respectively, meaning double selectivity (Table 1; Additional file 1: Video S1, Additional file 2: Video S2 and Additional file 3: Video S3 for compound 4 and Additional file 4: Video S4, Additional file 5: Video S5 and Additional file 6: Video S6 for compound 6). Compounds 14, 9, 11 and 1 also elicited good activity with SI values ranging from 0.7 to 0.5 compared to edelfosine activity. Unfortunately all of these were more toxic than edelfosine.

Ten alkane-1,2-diamines were also tested, compounds 16-25 (Table 2). Compounds 17, 18, 23 and 24 were more potent than edelfosine, with relative potency values of 1.2, 1.2, 1.2 and 1.4, respectively. Compounds 23 and 24 were more toxic than edelfosine, while SIs of compounds 17 and 18 were 1.7 and 1.4, respectively (Table 2: Additional file 7: Video S7, Additional file 8: Video S8 and Additional file 9: Video S9 for compound 17 and Additional file 10: Video S10, Additional file 11: Video S11 and Additional file 12: Video S12 for compound 18). Compounds 25, 16, 20 and 22 have also shown good activity, ranging from 0.7 to 0.5 compared to edelfosine activity. Compound $\mathbf{1 6}$ cytotoxicity was similar to edelfosine while the other three were more toxic.

Compounds, 4, 6, 17 and 18, which reached the highest SI values, seemed to act in a dose- and time-dependent manner, since larval viability was progressively inhibited to completion as dose and time increased. As a consequence of the global consideration of SI values, larval viability measured by XTT and motility examination, the four compounds were selected for evaluation of their in vivo efficacy in infected mice.

\section{Efficacy of aminoalcohols and diamines against $S$. venezuelensis experimental infections in mice}

The in vivo anti-Strongyloides efficacy of compounds 4 , 6, 17 and 18 is summarized in Table 3 and Fig. 2. Aminoalcohol 6 induced parthenogenetic female burden reduction of $59 \%$ (Fig. 2a) and significant reductions in egg numbers in faeces on days 6 and 7 p.i. ranging from 35 to $51 \%$, respectively (Table 3 ) compared to infection controls. Administration of diamine $\mathbf{1 8}$ resulted in reduction in the number of eggs in faeces on day 7 p.i (50\%; Table 3) and moderate but not significant reduction of parthenogenetic females in the gut (25\%; Fig. 2b). Despite aminoalcohol $\mathbf{4}$ and diamine $\mathbf{1 7}$ inducing a moderate reduction of eggs in faeces (45 and $21 \%$, respectively) they failed to reduce female burdens on day 7 
Table 1 In vitro efficacy and selectivity measured by XTT of alkane aminoalcohol derivatives against S. venezuelensis third-stage larvae (L3)

\begin{tabular}{|c|c|c|c|c|c|c|c|c|}
\hline Compound & $\mathrm{R}^{1}$ & $R^{2}$ & $R^{3}$ & $n$ & $\begin{array}{l}\text { Efficacy against } \mathrm{L} 3 \\
\mathrm{LC}_{50}(\mu \mathrm{M}) \\
\text { Mean } \pm \text { SEM }\end{array}$ & $P_{E D E L}^{a}$ & $\begin{array}{l}\text { Cytotoxicity } \\
\mathrm{LC}_{50}(\mu \mathrm{M}) \\
\text { Mean } \pm \text { SEM }\end{array}$ & $\mathrm{SI}^{\mathrm{b}}$ \\
\hline 1 & $\mathrm{H}$ & $\mathrm{H}$ & $\mathrm{H}$ & 9 & $97.8 \pm 10.6$ & 0.5 & $17.4 \pm 0.4$ & 0.2 \\
\hline 2 & $\mathrm{H}$ & $\mathrm{H}$ & $\mathrm{H}$ & 13 & $348.4 \pm 1.5$ & 0.1 & $\mathrm{nt}$ & - \\
\hline 3 & $\mathrm{H}$ & $\mathrm{H}$ & $\mathrm{H}$ & 15 & $239.3 \pm 7.9$ & 0.2 & $\mathrm{nt}$ & - \\
\hline 4 & $\mathrm{H}$ & $\mathrm{H}$ & Et & 13 & $35.1 \pm 0.1^{c^{*}}$ & 1.4 & $52.0 \pm 5.3$ & 1.5 \\
\hline 5 & $\mathrm{H}$ & $\mathrm{H}$ & $\mathrm{Bu}$ & 9 & $297.6 \pm 5.4$ & 0.1 & $37.9 \pm 1.9$ & 0.1 \\
\hline 6 & $\mathrm{H}$ & $\mathrm{H}$ & $\mathrm{Bu}$ & 13 & $31.9 \pm 0.5^{\mathrm{d}^{*}}$ & 1.5 & $52.0 \pm 4.1$ & 1.6 \\
\hline 7 & $\mathrm{H}$ & $\mathrm{H}$ & $\mathrm{Bu}$ & 15 & $293.3 \pm 2.6$ & 0.1 & $10.0 \pm 1.5$ & $<0.1$ \\
\hline 8 & $\mathrm{H}$ & $\mathrm{H}$ & Hex & 9 & $122.7 \pm 6.4$ & 0.4 & $43.2 \pm 0.9$ & 0.4 \\
\hline 9 & $\mathrm{H}$ & $\mathrm{H}$ & Hex & 13 & $84.2 \pm 4.3$ & 0.5 & $10.9 \pm 1.3$ & 0.1 \\
\hline 10 & $\mathrm{H}$ & $\mathrm{H}$ & Hex & 15 & $112.5 \pm 5.3$ & 0.4 & $54.2 \pm 0.9$ & 0.5 \\
\hline 11 & $\mathrm{H}$ & Et & Et & 13 & $90.0 \pm 5.7$ & 0.5 & $2.2 \pm 2.2$ & $<0.1$ \\
\hline 12 & $\mathrm{H}$ & $\mathrm{Bu}$ & $\mathrm{Bu}$ & 9 & $169.0 \pm 9.2$ & 0.2 & $63.7 \pm 1.2$ & 0.4 \\
\hline 13 & $\mathrm{H}$ & $\mathrm{Bu}$ & $\mathrm{Bu}$ & 13 & $192.1 \pm 7.7$ & 0.2 & $\mathrm{nt}$ & - \\
\hline 14 & $\mathrm{Bn}$ & $\mathrm{H}$ & $\mathrm{H}$ & 13 & $67.6 \pm 6.3$ & 0.7 & $30.2 \pm 0.3$ & 0.4 \\
\hline 15 & $\mathrm{Bn}$ & $\mathrm{H}$ & $\mathrm{Bu}$ & 13 & $232.0 \pm 4.5$ & 0.2 & $\mathrm{nt}$ & - \\
\hline Edelfosine & & & & & $49.6 \pm 0.5$ & 1.0 & $40.7 \pm 7.1$ & 0.8 \\
\hline
\end{tabular}

Abbreviations: Bn Benzyl, Bu Butyl, Et Ethyl, $n t$ not tested, SEM standard error of the mean, $\mathrm{R}^{1}$ substituent on the hydroxyl group; $\mathrm{R}^{2}$ and $\mathrm{R}^{3}$ substituents on the amine group

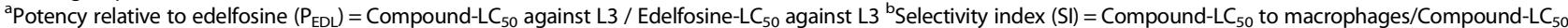
against L3

${ }^{c_{*}}$ Significant increase in $\mathrm{P}_{\mathrm{EDEL}}$ compared to edelfosine (ANOVA $F_{(15,62)}=413.82, P<0.001 ; \mathrm{HDS} P=0.008$ )

$d_{*}$ Significant increase in $P_{\text {EDEL }}$ compared to edelfosine (ANOVA $F_{(15,62)}=413.82, P<0.001 ;{ }^{\text {b }} \mathrm{HDS} P=0.002$ )

Table 2 In vitro efficacy and selectivity measured by XTT of alkane diamines derivatives against S. venezuelensis third-stage larvae (L3)

\begin{tabular}{|c|c|c|c|c|c|c|c|c|}
\hline Compound & $\mathrm{R}^{1}$ & $R^{2}$ & $\mathrm{R}^{3}$ & $n$ & $\begin{array}{l}\text { Efficacy against } L 3 \\
L_{50}(\mu M) \\
\text { Mean } \pm \text { SEM }\end{array}$ & $P_{E D E L}^{a}$ & $\begin{array}{l}\text { Cytotoxicity } \\
\mathrm{LC}_{50}(\mu \mathrm{M}) \\
\text { Mean } \pm \mathrm{SEM}\end{array}$ & $S \mathrm{~S}^{\mathrm{b}}$ \\
\hline 16 & $\mathrm{H}$ & $\mathrm{H}$ & $\mathrm{H}$ & 13 & $75.0 \pm 4.1$ & 0.6 & $40.1 \pm 0.4$ & 0.5 \\
\hline 17 & $\mathrm{H}$ & $\mathrm{H}$ & Boc & 9 & $39.0 \pm 2.9^{c^{*}}$ & 1.2 & $66.6 \pm 2.2$ & 1.7 \\
\hline 18 & $\mathrm{H}$ & $\mathrm{H}$ & Boc & 13 & $39.1 \pm 4.7^{c^{*}}$ & 1.2 & $56.2 \pm 3.3$ & 1.4 \\
\hline 19 & $\mathrm{H}$ & $\mathrm{H}$ & Boc & 15 & $45.7 \pm 9.2$ & 1.0 & $36.8 \pm 2.8$ & 0.8 \\
\hline 20 & $\mathrm{H}$ & Et & $\mathrm{H}$ & 13 & $95.4 \pm 1.5$ & 0.5 & $10.5 \pm 1.4$ & 0.1 \\
\hline 21 & $\mathrm{H}$ & $\mathrm{Bu}$ & $\mathrm{H}$ & 13 & $148.3 \pm 3.3$ & 0.3 & $15.5 \pm 1.2$ & 0.1 \\
\hline 22 & $\mathrm{H}$ & Hex & $\mathrm{H}$ & 13 & $83.6 \pm 3.1$ & 0.5 & $5.2 \pm 0.5$ & 0.0 \\
\hline 23 & $\mathrm{H}$ & Hex & Boc & 13 & $38.9 \pm 4.6^{C^{*}}$ & 1.2 & $4.9 \pm 0.8$ & 0.1 \\
\hline 24 & Et & Et & $\mathrm{H}$ & 13 & $33.4 \pm 0.7^{d^{*}}$ & 1.4 & $13.2 \pm 1.7$ & 0.3 \\
\hline 25 & Hex & Hex & Boc & 13 & $67.8 \pm 7.1$ & 0.7 & $7.6 \pm 0.6$ & 0.1 \\
\hline Edelfosine & & & & & $49.6 \pm 0.5$ & 1.0 & $40.7 \pm 7.1$ & 0.8 \\
\hline
\end{tabular}

Abbreviations: Bn Benzyl, Bu butyl, Et ethyl, Hex hexyl, Boc, tert-butoxycarbonyl, SEM standard error of the mean; R1 and R2 substituents on the amine at position

$\mathrm{C}-1$; R3 substituents on the amine at position $\mathrm{C}-2$

${ }^{\mathrm{a}}$ Potency relative to edelfosine $\left(\mathrm{P}_{\mathrm{EDL}}\right)=$ Compound-LC 50 against $\mathrm{L} 3 /$ Edelfosine- $L \mathrm{C}_{50}$ against $\mathrm{L} 3$

${ }^{\mathrm{b}}$ Selectivity index $(\mathrm{SI})=$ Compound-LC $\mathrm{C}_{50}$ to macrophages/Compound-LC $\mathrm{C}_{50}$ against $\mathrm{L} 3$

$c^{*}$ Significant increase in $P_{E D E L}$ compared to edelfosine ANOVA: $F_{(10,72)}=216.85, P<0.001 ;$ HDS $P=0.001$

$c^{*}$ Significant increase in $\mathrm{P}_{\mathrm{EDEL}}$ compared to edelfosine ANOVA: $F_{(10,72)}=216.85, P<0.001 ; \mathrm{HDS} P<0.001$ 
Table 3 Reduction in egg per gram of faeces (EPGF) in mice infected with 3,000 S. venezuelensis L3 after treatment with aminoalcohol derivatives $\mathbf{4}$ and $\mathbf{6}$ and diamine derivatives $\mathbf{1 7}$ and $\mathbf{1 8}$ for five days at a dose of $20 \mathrm{mg} / \mathrm{kg}$, and ivermectin $0.2 \mathrm{mg} / \mathrm{kg}$

\begin{tabular}{|c|c|c|c|c|c|c|c|c|}
\hline \multirow[t]{2}{*}{ Groups } & \multicolumn{2}{|l|}{ EPGF on day 5} & \multicolumn{2}{|l|}{ EPGF on day 6} & \multirow{2}{*}{$\begin{array}{l}\text { HDS } \\
P\end{array}$} & \multirow{2}{*}{$\begin{array}{l}\text { EPGF on day } 7 \\
\text { (Mean } \pm \text { SEM) }\end{array}$} & \multirow[b]{2}{*}{ Reduction (\%) } & \multirow{2}{*}{$\begin{array}{l}\mathrm{HDS} \\
P\end{array}$} \\
\hline & $($ Mean \pm SEM) & Reduction (\%) & (Mean \pm SEM) & Reduction (\%) & & & & \\
\hline \multicolumn{9}{|l|}{ Experiment 1} \\
\hline Infected & $2,020 \pm 430$ & - & $24,800 \pm 5,210$ & - & & $12,5150 \pm 9,200$ & - & \\
\hline Ivermectin & $5,240 \pm 580$ & $\mathrm{nr}$ & $330 \pm 110$ & $99^{a}$ & $<0.001$ & $0 \pm 0$ & $100^{a}$ & $<0.001$ \\
\hline Aminoalcohol 4 & $3,830 \pm 570$ & $\mathrm{nr}$ & $20,220 \pm 3,080$ & 18 & 0.274 & $68,980 \pm 12,810$ & $45^{a}$ & $<0.001$ \\
\hline Aminoalcohol 6 & $4,720 \pm 900$ & $\mathrm{nr}$ & $16,160 \pm 1970$ & $35^{\mathrm{a}}$ & 0.044 & $61,680 \pm 1,917$ & $51^{a}$ & $<0.001$ \\
\hline ANOVA & $\begin{array}{l}F_{(3,28)}=3.28 \\
P=0.051\end{array}$ & & $\begin{array}{l}F_{(3,28)}=13.42 \\
P<0.001\end{array}$ & & & $\begin{array}{l}F_{(3,28)}=45.31 \\
P<0.001\end{array}$ & & \\
\hline \multicolumn{9}{|l|}{ Experiment 2} \\
\hline Infected & $3,190 \pm 300$ & - & $11,060 \pm 1,710$ & - & & $82,820 \pm 5,364$ & - & \\
\hline Ivermectin & $2,950 \pm 300$ & 8 & $160 \pm 90$ & $99^{a}$ & $<0.001$ & $80 \pm 50$ & $100^{\mathrm{a}}$ & $<0.001$ \\
\hline Diamine 17 & $2,715 \pm 410$ & 15 & $10,890 \pm 1,200$ & 2 & 0.912 & $65,520 \pm 7,037$ & $21^{\mathrm{a}}$ & 0.025 \\
\hline Diamine $\mathbf{1 8}$ & $3,410 \pm 520$ & $\mathrm{nr}$ & $8,110 \pm 430$ & 27 & 0.060 & $41,450 \pm 5,382$ & $50^{\mathrm{a}}$ & $<0.001$ \\
\hline ANOVA & $\begin{array}{l}F_{(3,28)}=0.59 ; \\
P=0.625\end{array}$ & & $\begin{array}{l}F_{(3,28)}=23.03 \\
P<0.001\end{array}$ & & & $\begin{array}{l}F_{(3,28)}=47.94 ; \\
P<0.001\end{array}$ & & \\
\hline
\end{tabular}

Abbreviations: HDS Tukey's honest significance test, $n r$ no reduction, SEM standard error of the mean

${ }^{a}$ Significant reduction compared to infected control group

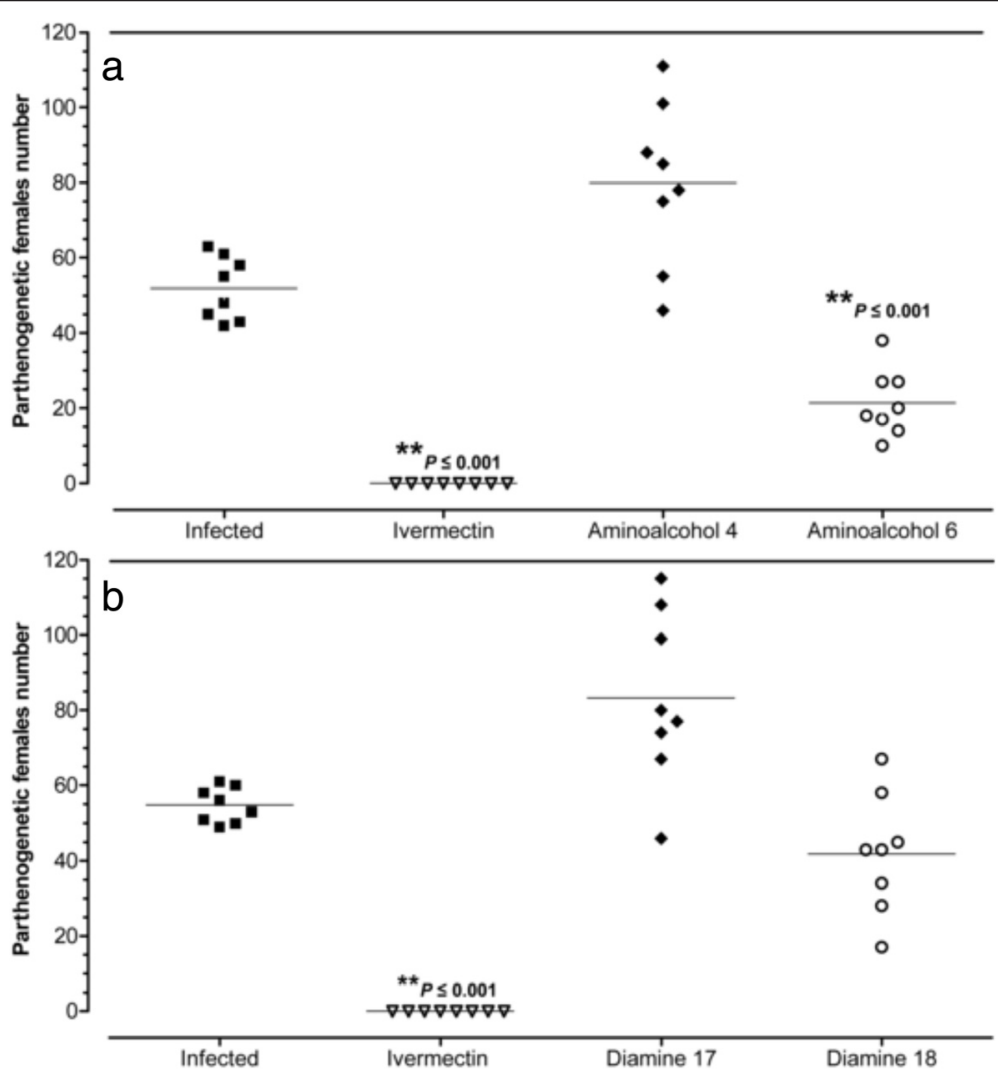

Fig. 2 Number of parthenogenetic females on day 7 post-infection. a Mice treated with $20 \mathrm{mg} / \mathrm{kg}$ of aminoalcohols 4 and $\mathbf{6}\left(\right.$ ANOVA $F_{(2,28)}=62.93$, $P<0.001$ ). b Mice treated with $20 \mathrm{mg} / \mathrm{kg}$ of diamines 17 and 18 (ANOVA $F_{(3,28)}=48.03, P<0.001$ ). Worms were recovered from the intestine of mice infected with 3,000 S. venezuelensis $\mathrm{L} 3$ and treated during five days. Each point represents data from individual mice and horizontal bars indicate the means; stars indicate significant reduction of worm recovery compared to infected control 
p.i. (Table 3; Fig. 2). During the experiments, all mice used (64/64) remained alive and there was not evidence of any symptoms of severe pain, excessive distress, suffering or an impending death in any of the animals. Daily oral administration of each compound $(20 \mathrm{mg} / \mathrm{kg} /$ day) and ivermectin $(0.2 \mathrm{mg} / \mathrm{kg})$ were well tolerated by animals in all experiments.

\section{Discussion}

To the best of our knowledge, this study represents the first insight into therapeutic use of alkane aminoalcohols and diamines against a nematode such as S. venezuelensis. Synthetic new compounds developed for cancer or organ transplantation are very attractive and untapped resources for the development of new drugs for neglected diseases such as the strongyloidiasis. Long chain-aminoalcohols and diamines are sphingosine-derivatives that have been considered as target molecules for development of new drugs showing cytotoxicity against neoplastic cells [35], and possessing anti-inflammatory properties $[34,36]$ and ability to kill infectious agents [18, 24, 37]. However, they have never been used against nematodes such as Strongyloides spp. These compounds have structural resemblances to anticancer alkylphospholipids with anthelminthic activity against S. mansoni and S. venezuelensis [38]. Therefore, we used the alkylphospholipid edelfosine as control for in vitro experiments.

We have studied the structure-activity relationships in both type I and type II compounds. We found that aminoalcohols $\mathbf{4}$ and $\mathbf{6}$ with a palmitoyl chain (n-hexadecan1-ol) and the diamines $\mathbf{1 7}$ and $\mathbf{1 8}$ with chains of lauroyl (n-dodeca-1-ol) and palmitoyl, respectively, showed a more potent activity against $S$. venezuelensis L3, with low cytotoxicity for mammal macrophages and high selectivity indices (SIs) indicating their potential efficacy. Concerning aminoalcohol derivatives (compounds 1-15) the following comparisons of results can be performed. Examination of the substituents of the 2-amino group indicated the preference for a small- (ethyl) to medium- (butyl) sized alkyl group in the secondary amine, as seen in derivatives $\mathbf{4}$ and 6, suggesting a decrease in the activity with increase in substituent size increase, compound 9 activity. Interestingly, compound 6 (2-n-butylamino-hexadecan-1-ol) was found to be less toxic and had a better SI than the reference drug edelfosine. Compound $\mathbf{6}$ was also the most potent and selective compound among the aminoalcohols tested. Transformation of the secondary amines $\mathbf{4}$ and $\mathbf{6}$ into their respective tertiary analogues $\mathbf{1 1}$ and $\mathbf{1 3}$ led to a fair reduction of activity. Regarding the 1,2-alkanediamines 16-25 (Table 2), the most potent compound against larvae was the diamine $\mathbf{2 4}$, a compound with a primary amine at position $\mathrm{C}-2$ and a tertiary one at $\mathrm{C}-1$; unfortunately, it showed a high cytotoxicity. Compounds 17, 18 and 23, the three Boc-protected diamines, showed similar efficacy against L3; the last one was highly toxic, and the other two had SIs of 1.7 and 1.4, respectively. Compounds 17 and 18 only differed in the size of the chain, with respective n-values of 9 and 13; in this case, a small size chain gave less toxicity. In summary, based on the ten alkanediamines tested, it can be concluded that there is a preference for compounds with a Boc-protecting group attached to the 2-amino group in the in vitro activity assays.

Inhibition of the viability of L3 induced by compound $\mathbf{6}$ increased in a dose- and time-dependent manner, demonstrated using both XTT technique and motility records. Lipophilic diamine and aminoalcohol derivatives containing chains with 13 carbon atoms demonstrate activity against $T$. cruzi trypomastigotes [24], indicating they possess the best range of activity. It seems that the 16-carbon chain length could be involved in the drug's increased solubility, absorption and harmful action, leading to the dead of the larvae [39]. We observed that only aminoalcohol 6, containing an alkyl chain with a 16-carbon atom chain and a butyl radical, displayed efficacy against $S$. venezuelensis infection in mice. Although this activity was less effective than ivermectin, the choice drug for strongyloidiasis treatment, our data indicate that oral treatment with aminoalcohol 6 significantly decreases both, the recovered adult parthenogenetic females in the small intestine and the number of eggs per gram of faeces. Aminoalcohol $\mathbf{6}$ has also demonstrated the highest activity against three T. cruzi strains in cultures [21].

Alkylphospholipids, aminoalcohols and diamines have the ability to interact with membrane lipids, allowing their penetration into the parasite where they may disturb cell metabolism and integrity [24]. The pro-apoptotic mechanism was also described in edelfosine $[38,40]$ and in long chain aminoalcohols [41]. Further studies should be conducted to determine the mechanisms of action. Despite aminoalcohol 6 did not exhibit activity comparable to ivermectin, combinations with current drugs may result in useful synergistic interactions.

\section{Conclusions}

In conclusion, we have reported the strongyloidicidal activity of two series of sphingosine-related compounds, 15 aminoalkanols and 10 alkanediamines, against $S$. venezuelensis using L3 cultures and a strongyloidiasis murine model to search for promising lead compounds that can be optimized to improve their potency and selectivity. This preliminary study introduces aminoalcohol 6 as a suitable prototype for the design of new antiStrongyloides drugs. However, further in vivo studies need to be conducted in order to confirm the outcomes achieved and its utility in therapy against strongyloidiasis and other geohelminthiases. 


\section{Additional files}

Additional file 1: Video S1. Motility in S. venezuelensis $L 3$ treated with aminoalcohol $\mathbf{4}$ at 24 h post treatment under optical microscope. (MP4 $6713 \mathrm{~kb}$ )

Additional file 2: Video S2. Motility in S. venezuelensis L3 treated with aminoalcohol $\mathbf{4}$ at $48 \mathrm{~h}$ post treatment under optical microscope. (MP4 $6623 \mathrm{~kb}$ )

Additional file 3: Video S3. Motility in S. venezuelensis L3 treated with aminoalcohol $\mathbf{4}$ at $72 \mathrm{~h}$ post treatment under optical microscope. (MP4 $6562 \mathrm{~kb}$ )

Additional file 4: Video S4. Motility in S. venezuelensis L3 treated with aminoalcohol 6 at 24 h post treatment under optical microscope. (MP4 6999 kb)

Additional file 5: Video S5. Motility in S. venezuelensis $L 3$ treated with aminoalcohol 6 at $48 \mathrm{~h}$ post treatment under optical microscope. (MP4 $6.87 \mathrm{mb}$ )

Additional file 6: Video S6. Motility in S. venezuelensis L3 treated with aminoalcohol $\mathbf{6}$ at $72 \mathrm{~h}$ post treatment under optical microscope. (MP4 $6772 \mathrm{~kb})$

Additional file 7: Video S7. Motility in S. venezuelensis L3 treated with diamine $\mathbf{1 7}$ at $24 \mathrm{~h}$ post treatment under optical microscope. (MP4 $7218 \mathrm{~kb}$ )

Additional file 8: Video S8. Motility in S. venezuelensis L3 treated with diamine $\mathbf{1 7}$ at $48 \mathrm{~h}$ post treatment under optical microscope. (MP4 7202 kb)

Additional file 9: Video S9. Motility in S. venezuelensis $L 3$ treated with diamine $\mathbf{1 7}$ at $72 \mathrm{~h}$ post treatment under optical microscope. (MP4 7227 kb)

Additional file 10: Video S10. Motility in S. venezuelensis L3 treated with diamine $\mathbf{1 8}$ at $24 \mathrm{~h}$ post treatment under optical microscope. (MP4 7206 kb)

Additional file 11: Video S11. Motility in S. venezuelensis L3 treated with diamine $\mathbf{1 8}$ at $48 \mathrm{~h}$ post treatment under optical microscope. (MP4 7297 kb)

Additional file 12: Video S12. Motility in S. venezuelensis L3 treated with diamine $\mathbf{1 8}$ at $72 \mathrm{~h}$ post treatment under optical microscope. (MP4 $7365 \mathrm{~kb}$ )

\section{Abbreviations}

ANOVA, analysis of variance; Boc, tert-butoxycarbonyl protecting group; HDS, Tukey's honest significance test; HTLV-1, Human T-lymphotropic virus-1; L1, firststage larva or rhabditiform larva; $\mathrm{L} 3$ third-stage larva or filariform larva; $\mathrm{LC}_{50}$,

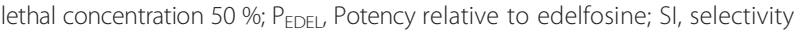
index; XTT, 2,3-bis-(2-methoxy-4-nitro-5-sulfophenyl)-2H-tetrazolium-5carboxanilide)

\section{Acknowledgements}

We want to thank J.J. Muñoz Quijano for video production and edition, and F.J. Burguillo Muñoz, University of Salamanca for the statistical analysis support. We also acknowledge the support of Manasa Bhatta (Emory University) for the English edition and the editorial help for the style correction.

\section{Funding}

Financial support came from Proyectos Integrados IBSAL (IBY15/00003; Salamanca, Spain), ISCIII-FIS (RICET VI PN de I + D + I 2013-2016 FEDER: RD12/0018/0002) and CIETUS-University of Salamanca. LAB was supported by International Fellowship USAL-Banco Santander and Human Capital ProgramCONCICYT, Chile.

\section{Availability of data and materials}

The datasets supporting the conclusions of this article are included within the article.

\section{Authors' contributions}

EO and ASF designed the compounds of the study. RE and LAB synthesized and characterized the compounds tested. JL-A and AM designed the in vitro and in vivo experiments. ALL-C, JR-C, BV and PF-S performed the biological assays. EO, JL-A, ALL-C, JR-C, BV, PF-S, ASF and AM analysed and interpreted the data. JL-A, EO, JR-C and ALL-C drafted the first manuscript. ASF and AM critically revised the manuscript. All authors read and approved the final manuscript.

\section{Competing interests}

The authors declare that they have no competing interests.

\section{Consent for publication}

Not applicable.

\section{Ethics approval and consent to participate}

The University of Salamanca's Ethics Committee approved the procedures involving animals used in this study (Protocol: 48531).

\section{Author details}

'Parasite and Molecular Immunology Laboratory, Tropical Disease Research Centre, University of Salamanca (IBSAL-CIETUS), Avda. Licenciado Méndez Nieto s/n, 37007 Salamanca, Spain. ${ }^{2}$ Department of Pharmaceutical Chemistry, Faculty of Pharmacy (IBSAL-CIETUS), University of Salamanca, 37007 Salamanca, Spain. ${ }^{3}$ Present Address: Departamento de Ciencias Farmacéuticas, Facultad de Ciencias, Universidad Católica del Norte, Antofagasta, Chile. ${ }^{4}$ Present Address: Centro de Investigación en Salud para el Trópico (CIST), Carretera Troncal del Caribe, Sector Mamatoco, Santa Marta, Magdalena, Colombia. ${ }^{5}$ Present Address: Facultad de Medicina, Universidad Cooperativa de Colombia, Carretera Troncal del Caribe, Sector Mamatoco, Santa Marta, Magdalena, Colombia.

Received: 24 January 2016 Accepted: 16 June 2016

Published online: 28 June 2016

\section{References}

1. Schär F, Trostdorf U, Giardina F, Khieu V, Muth S, Marti H, Vounatsou P, Odermatt P. Strongyloides stercoralis: Global Distribution and Risk Factors. PLoS Negl Trop Dis. 2013;7:e2288.

2. Krolewiecki AJ, Lammie P, Jacobson J, Gabrielli AF, Levecke B, Socias E, Arias LM, Sosa N, Abraham D, Cimino R, Echazú A, Crudo F, Vercruysse J, Albonico M. A public health response against Strongyloides stercoralis: time to look at soil-transmitted helminthiasis in full. PLoS Negl Trop Dis. 2013;7:e2165.

3. WHO. Working to overcome the global impact of neglected tropical diseases Summary. Wkly Epidemiol Rec. 2011;86:113-20.

4. Vadlamudi RS, Chi DS, Krishnaswamy G. Intestinal strongyloidiasis and hyperinfection syndrome. Clin Mol Allergy. 2006;4:8.

5. Viney ME, Lok JB. Strongyloides spp. WormBook. 2007;23:1-15. Review. PMID: 18050491

6. Reece JJ, Siracusa MC, Scott AL. Innate immune responses to lung-stage helminth infection induce alternatively activated alveolar macrophages. Infect Immun. 2006;74:4970-81.

7. Fardet L, Généreau T, Poirot JL, Guidet B, Kettaneh A, Cabane J. Severe strongyloidiasis in corticosteroid-treated patients: case series and literature review. J Infect. 2007:54:18-27.

8. Feely NM, Waghorn DJ, Dexter T, Gallen I, Chiodini P. Strongyloides stercoralis hyperinfection: difficulties in diagnosis and treatment. Anaesthesia. 2010;65: 298-301.

9. Suputtamongkol Y, Premasathian N, Bhumimuang K, Waywa D, Nilganuwong S, Karuphong E, Anekthananon T, Wanachiwanawin D, Silpasakorn S. Efficacy and safety of single and double doses of ivermectin versus 7day high dose albendazole for chronic strongyloidiasis. PLoS Negl Trop Dis. 2011;5:e1044.

10. Carvalho EM, da Fonseca Porto A. Epidemiological and clinical interaction between HTLV-1 and Strongyloides stercoralis. Parasite Immunol. 2004;26: 487-97.

11. Hays R, Esterman A, McDermott R. Type 2 Diabetes Mellitus Is Associated with Strongyloides stercoralis Treatment Failure in Australian Aboriginals. PLoS Negl Trop Dis. 2015;9:e0003976.

12. Salam RA, Haider BA, Humayun $Q$, Bhutta ZA. Effect of administration of antihelminthics for soil-transmitted helminths during pregnancy. Cochrane Database Syst Rev. 2015:(6):CD005547. doi:10.1002/14651858.CD005547. pub3.. Review. PMID: 26087057. 
13. Speich B, Ali SM, Ame SM, Bogoch II, Alles R, Huwyler J, Albonico M, Hattendorf J, Utzinger J, Keiser J. Efficacy and safety of albendazole plus ivermectin, albendazole plus mebendazole, albendazole plus oxantel pamoate, and mebendazole alone against Trichuris trichiura and concomitant soil-transmitted helminth infections: a four-arm, randomised controlled trial. Lancet Infect Dis. 2015;15:277-84.

14. Vercruysse J, Albonico M, Behnke JM, Kotze AC, Prichard RK, McCarthy JS, Montresor A, Levecke B. Is anthelmintic resistance a concern for the control of human soil-transmitted helminths? Int J Parasitol Drugs Drug Resist. 2011;1:14-27.

15. Osei-Atweneboana MY, Awadzi K, Attah SK, Boakye DA, Gyapong JO, Prichard RK. Phenotypic evidence of emerging ivermectin resistance in Onchocerca volvulus. PLoS Negl Trop Dis. 2011;5:e998.

16. Bourguinat C, Kamgno J, Boussinesq M, Mackenzie CD, Prichard RK, Geary TG. Analysis of the mdr-1 gene in patients co-infected with Onchocerca volvulus and Loa loa who experienced a post-ivermectin serious adverse event. Am J Trop Med Hyg. 2010;83:28-32.

17. del Olmo E, Molina-Salinas GM, Escarcena R, Alves M, López-Pérez JL, HernándezPando R, Said-Fernández S, Feliciano AS. Simple dihydrosphyngosine analogues with potent activity against MDR-Mycobacterium tuberculosis. Bioorg Med Chem Lett. 2009;19:5764-68.

18. Howarth J, Lloyd DG. Simple 1,2-aminoalcohols as strain-specific antimalarial agents. J Antimicrob Chemother. 2000;46:625-8.

19. del Olmo E, Alves M, López JL, Inchaustti A, Yaluff G, Rojas De Arias A, San Feliciano A. Leishmanicidal activity of some aliphatic diamines and aminoalcohols. Bioorg Med Chem Lett. 2002;12:659-62.

20. del Olmo E, Díaz-González R, Escarcena R, Carvalho L, Bustos LA, Navarro M, Feliciano AS. Diamine and aminoalcohol derivatives active against Trypanosoma brucei. Bioorg Med Chem Lett. 2012;22:440-3.

21. Legarda-Ceballos AL, del Olmo E, López-Abán J, Escarcena R, Bustos LA, FonsecaBerzal C, Gómez-Barrio A, Dib JC, San Feliciano A, Muro A. Trypanocidal activity of long chain diamines and aminoalcohols. Molecules. 2015;20:11554-68.

22. Giordani RB, Araujo DP, Duarte M, Zuanazzi JA, Tasca T, De Almeida MV. Antiprotozoal activity of diamine derivatives. Biomed Pharmacother. 2011;65:60-2.

23. Derita M, del Olmo E, Barboza B, García-Cadenas AE, López-Pérez JL, Andújar S, Enriz D, Zacchino S, San Feliciano A. Synthesis, bioevaluation and structural study of substituted phthalazin-1(2H)-ones acting as antifungal agents. Molecules. 2013:18:3479-501.

24. Fernandes FS, Rezende Junior CO, Fernandes TS, da Silveira LS, Rezende CA, De Almeida MV, de Paula RG, Rodrigues V, Da Silva Filho AA, Couri MR. Anthelmintic effects of alkylated diamines and amino alcohols against Schistosoma mansoni. Biomed Res Int. 2013;2013:783490.

25. Sánchez-Blanco A, Rodríguez-Matellán AG, Reis-Sobreiro M, Sáenz-Narciso B, Cabello J, Mohler WA, Mollinedo F. Caenorhabditis elegans as a platform to study the mechanism of action of synthetic antitumor lipids. Cell Cycle. 2014;13:3375-89.

26. Gajate C, Mollinedo F. Edelfosine and perifosine induce selective apoptosis in multiple myeloma by recruitment of death receptors and downstream signaling molecules into lipid rafts. Blood. 2007;109:711-9.

27. Charan J, Kantharia ND. How to calculate sample size in animal studies? J Pharmacol Pharmacother. 2013;4:303-6.

28. Festing MF, Altman DG. Guidelines for the design and statistical analysis of experiments using laboratory animals. ILAR J. 2002:43:244-58.

29. Martins WA, Melo AL, Nicoli JR, Cara DC, Carvalho MA, Lana MA, Vieira EC, Farias LM. A method of decontaminating Strongyloides venezuelensis larvae for the study of strongyloidiasis in germ-free and conventional mice. J Med Microbiol. 2000;49:387-90.

30. Rebollo O, del Olmo E, Ruiz G, López-Pérez JL, Giménez A, San FA. Leishmanicidal and trypanocidal activities of 2-aminocyclohexanol and 1,2cyclohexanediamine derivatives. Bioorg Med Chem Lett. 2008;18:184-7.

31. Rojas-Caraballo J, López-Abán J, Pérez Del Villar L, Vizcaíno C, Vicente B, Fernández-Soto P, del Olmo E, Patarroyo MA, Muro A. In vitro and in vivo studies for assessing the immune response and protection-inducing ability conferred by Fasciola hepatica-derived synthetic peptides containing B- and T-cell epitopes. PLoS One. 2014;9:e105323.

32. Gómez-Ayala S, Castrillón JA, Palma A, Leal SM, Escobar P, Bahsas A Synthesis, structural elucidation and in vitro antiparasitic activity against Trypanosoma cruzi and Leishmania chagasi parasites of novel tetrahydro-1benzazepine derivatives. Bioorg Med Chem. 2010;18:4721-39.
33. Yepes E, Varela-M RE, López-Abán J, Dakir El H, Mollinedo F, Muro A. In vitro and in vivo anti-schistosomal activity of the alkylphospholipid analog edelfosine. PLoS One. 2014;9:e109431.

34. Reis EF, Castro SB, Alves CC, Oliveira EE, Correa TA, Almeida MV, Ferreira AP. Lipophilic amino alcohols reduce carrageenan-induced paw edema and anti-OVA DTH in BALB/c mice. Int Immunopharmacol. 2013;17:727-32.

35. Nishizaki T, Kanno T, Tsuchiya A, Kaku Y, Shimizu T, Tanaka A. 1-[2-(2Methoxyphenylamino) ethylamino]-3-(naphthalene-1-yloxy)propan-2-ol may be a promising anticancer drug. Molecules. 2014;19:21462-72.

36. Pontiki E, Hadjipavlou-Litina D, Patsilinakos A, Tran TM, Marson CM. Pteridine-2,4-diamine derivatives as radical scavengers and inhibitors of lipoxygenase that can possess anti-inflammatory properties. Future Med Chem. 2015;7:1937-51

37. Pérez-Meseguer J, del Olmo E, Alanis-Garza B, Escarcena R, Garza-González E, Salazar-Aranda R, Feliciano AS, de Torres NW. Synthesis of leubethanol derivatives and evaluation against Mycobacterium tuberculosis. Bioorg Med Chem. 2012;20:4155-63.

38. Yepes E, Varela-M RE, López-Abán J, Rojas-Caraballo J, Muro A, Mollinedo F. Inhibition of granulomatous inflammation and prophylactic treatment of schistosomiasis with a combination of edelfosine and praziquantel. PLoS Negl Trop Dis. 2015;9:e0003893.

39. Carvalho CO, Chagas AC, Cotinguiba F, Furlan M, Brito LG, Chaves FC, Stephan MP, Bizzo HR, Amarante AF. The anthelmintic effect of plant extracts on Haemonchus contortus and Strongyloides venezuelensis. Vet Parasitol. 2012;183:260-8

40. Varela-M RE, Villa-Pulgarín JA, Yepes E, Müller I, Modolell M, Muñoz DL, Robledo SM, Muskus CE, López-Abán J, Muro A, Vélez ID, Mollinedo F. In vitro and in vivo efficacy of ether lipid edelfosine against Leishmania spp. and SbV-resistant parasites. PLoS Negl Trop Dis. 2012;6:e1612.

41. del Olmo E, Macho A, Alves M, López JL, el Banoua F, Muñoz E, San Feliciano A. Long-chain aminoalcohol and diamine derivatives induce apoptosis through a caspase-3 dependent pathway. Bioorg Med Chem Lett. 2002:12:2621-6.

\section{Submit your next manuscript to BioMed Central and we will help you at every step:}

- We accept pre-submission inquiries

- Our selector tool helps you to find the most relevant journal

- We provide round the clock customer support

- Convenient online submission

- Thorough peer review

- Inclusion in PubMed and all major indexing services

- Maximum visibility for your research

Submit your manuscript at www.biomedcentral.com/submit 